\title{
A CRÍTICA ROMÂNTICA NO PENSAMENTO EDUCACIONAL DO JOVEM BENJAMIN
}

Priscilla Stuart da Silva*

Resumo: Este artigo procura abordar a crítica à cultura e às instituições de ensino feitas pelo jovem Benjamin diante das reformas técnicas realizadas no gymnasium e nas universidades alemãs. Benjamin parte da constatação de que há uma atrofia ou esgotamento do sentido formativo nas instituições educativas. Em seus escritos enquanto estudante, Benjamin recupera, com sua crítica, a necessidade de olhar a arte, a literatura, a educação, em suma, toda a cultura humana, como um conjunto reunido de experiências históricas. Em razão desse modo de pensar, o filósofo questiona, através de sua escrita e fala, qual o papel do jovem enquanto crítico. Desse modo, busca-se evidenciar como a necessidade da reforma espiritual é premente e a ideia da crítica do jovem pela sua escrita é indicada como tarefa (Aufgabe).

Palavras-chave: Crítica; Reforma educacional; Juventude; Formação; Walter Benjamin.

Resumen: Este artículo busca abordar las críticas a la cultura y las instituciones educativas hechas por el joven Benjamin ante las reformas técnicas llevadas a cabo en el gimnasio y en las universidades alemanas. Benjamin parte de la observación de que existe una atrofia o agotamiento del sentido formativo en las instituciones educativas. En sus escritos como estudiante, Benjamin recupera, con sus críticas, la necesidad de considerar el arte, la literatura, la educación, en resumen, toda la cultura humana, como un conjunto combinado de experiencias históricas. Debido a esta forma de pensar, el filósofo cuestiona, a través de su escritura y discurso, cuál es el papel del joven como crítico. De esta manera, busca mostrar cómo la necesidad de una reforma espiritual es urgente y la idea de la crítica del joven por su escritura se indica como una tarea (Aufgabe).

Palabras claves: Crítica; Reforma educativa; Juventud; Formación; Walter Benjamin.

Neste texto, procuramos delinear as implicações existentes entre a crítica que Benjamin realiza sobre o universo educacional em meio às reformas técnicas instauradas em sua época, bem como a tentativa de encontrar uma nova ideia de cultura e o papel ou tarefa do jovem nesse espaço pedagógico. Sua posição é a de um filósofo-educador do século XX, época na qual se "configura um movimento de ruptura perante a aridez da cultura exclusivamente científica, por um lado, e perante a ideia de especialização, por outro" (CANTINHO, 2016, p. 11).

\footnotetext{
* Doutora em Educação pela Universidade Federal de Santa Catarina -UFSC (2019). Atualmente é professora substituta do Departamento de Metodologia de Ensino da UFSC.

Contato: priscillastuart.di@gmail.com.
}

Benjamin não menciona os detalhes da reforma que se impunha nas instituições de sua época. Sabe-se, através de sua vinculação ao Movimento da Juventude Alemã, que discordava "das tradicionais $e$ conservadoras corporações estudantis das universidades alemãs", pois ele visava "à transformação radical da sociedade e da cultura pela ação de uma juventude esclarecida". Lutava, portanto - mediante uma visão de mundo calcada nas leituras românticas -, por "uma reforma pedagógica ampla, uma mudança de mentalidade dos jovens"; isso significava uma ruptura "decisiva para o renascimento da cultura alemã" (MURICY, 2009, p. 37).

A ideia de crítica na obra de Benjamin, aparece em seus escritos tanto em sua forma 
quanto em seu conteúdo, ou seja, "a crítica não é apenas o órganon de reflexão teórica, mas, simultaneamente, também o seu objeto. Ao desenvolver seu objeto, desenvolve-se e fundamenta a si mesma". Portanto, diante disso, fica claro que é preciso "conceber sua obra, na sua totalidade, como crítica" (STEINER, 2014, p. 241). A crítica como forma e como objeto aparece em seu pensamento desde os ensaios iniciais, em $A$ vida dos estudantes, passando pela crítica estética da obra de Goethe, pela poesia baudelairiana, pelo pensamento de Kant até a crítica presente nas teses sobre o conceito de história. Portanto, sabendo de seu comprometimento com o assunto, traçam-se aqui os primeiros passos de Benjamin sobre a crítica às instituições de ensino de seu país e sobre a ideia de crítica como modus operandi na vida do jovem, como forma de atuação frente às vicissitudes da formação.

Partindo, então, para seu emblemático ensaio, $A$ vida dos estudantes, encontra-se, grosso modo, uma crítica à cultura e às instituições de ensino diante das reformas técnicas realizadas pelo Estado no gymnasium e nas universidades alemãs. No meio disso, e através de sua escrita e fala, Benjamin questionará qual o papel do jovem enquanto crítico.

Em sua tese de doutorado, $O$ conceito de crítica de arte no romantismo alemão, Benjamin afirmará que crítico, por sua vez, é uma das expressões mais utilizadas pelos primeiros românticos e que "significava objetivamente produtivo", "criador a partir da clareza de consciência". "Ser crítico implica elevar o pensamento tão acima de todas as conexões a tal ponto que... surgiria o conhecimento da verdade" (BENJAMIN, 2011, p. 58-59; cf. G.S. I, 1, p. 51).

Essas expressões do pensamento romântico são importantes, pois os adeptos dessa escola foram os primeiros a pensar a crítica como gênero literário. E nessa esteira, como se revela em uma carta de 20 de janeiro de 1930, escrita em Paris e endereçada a Scholem, Benjamin pretendia reelaborar e reinventar a crítica como gênero literário e filosófico, esquecida há mais de 50 anos na Alemanha (BENJAMIN, 1994, p. 359). Esse desejo se manifesta desde seus primeiros escritos, e mais especificamente, em seu ensaio mais importante da juventude e já mencioando, $A$ vida dos estudantes. Nele, o filósofo defende que os estudantes manifestem uma atuação crítica a partir de dentro, de uma unidade ou um princípio consciente, "trata-se portanto, de unidade interior e não de crítica que vem de fora" (BENJAMIN, 2009a, p. 32; cf. G.S. II, 1, p. 76).

Segundo Bolle (1996), Benjamin parte da crítica ao saber institucionalizado porque ele próprio, em suas memórias de infância, desconhece uma relação mais afetiva com a escola, como se constata no aforismo $A$ escrivaninha, de Infância em Berlin por volta de 1900, no qual a formação está fora do âmbito educacional. Diante disso, Bolle se questiona se Benjamin não estaria criticando uma espécie de saber fingido ensinado na escola, pois, no seu entender, ela não consegue promover a formação. Em ensaios que antecedem ao da escrivaninha, como $A$ reforma escolar: um movimento cultural e $A$ vida dos estudantes, ele também percebe que a escola não consegue expressar a totalidade da vida humana. Em vista disso, 
Bolle afirma que:

Benjamin constata que a
universidade da época -
obedecendo aos interesses de uma
classe (a burguesia), perseguindo
metas utilitárias e se mantendo longe
dos escritores, dos artistas e das
fontes da vida religiosa - contraria e
obstrui a tentativa do estudante de
elaborar uma imagem própria do
mundo, um eidos que lhe possa
servir de organizador da experiência
e orientador da vida ética (BOLLE,
1996, p. 12).

Diante disso, em $A$ vida dos estudantes, há uma crítica às instituições educativas, pensadas como parte da constatação segundo a qual, na realidade, vigora uma atrofia ou esgotamento do sentido formativo das instituições educativas. Por isso, o diagnóstico de Readings é bastante relevante também no contexto da crítica ao modo de ensino dos professores no interior das universidades. $\mathrm{O}$ autor vai afirmar que a universidade de hoje não conta mais com um protagonista herói e não está mais comprometida com as grandes narrativas: as instituições de ensino estão regidas pelo signo da ruína. Apesar de indicar que "essas ruínas não precisam tornar-se objeto de uma nostalgia romântica, motivada pela perda da totalidade" (READINGS, 2002, p. 58), acredita-se que a crítica romântica pode ser muito construtiva para se pensar acerca do espaço que as instituições de ensino ocupam no mundo contemporâneo. Mesmo que a formação seja um modo de aprendizado da vida em geral, independente, em parte, da escola e da universidade, talvez sem elas não seja possível pensar a formação em sua amplitude.

A relação de Benjamin com as instituições de ensino é bastante complexa e repleta de consideráveis críticas, mas, logo de saída, é importante esclarecer que o filósofo não promovia seu pensamento debatendo contra a existência da escola e da universidade. Pelo contrário, sua denúncia se concentrará nas práticas realizadas no interior desses espaços. A ideia de educação, para ele, está vinculada à formação, ao formar (bilden), e essa expressão contém o sentido - atribuído pelo filósofo - para o indivíduo poder se realizar em sua forma mais plena. Diferente, portanto, de ficar restrito, pura e simplesmente, à ideia de ensino (instrução), limite esse, o foco de sua crítica. É bom lembrar que, em alemão, a palavra "ensino" significa lehren, ou seja, tem a mesma raiz de doutrina (Lehre). Isso significa que o termo sugere conter em si objetivos doutrinários, por vezes repletos de dogmatismos e ideologias, os quais Benjamin tenta combater. Por isso - e daí a relevância dessa brevíssima indicação conceitual -, quando o filósofo fala em educação, ele pensa em formação.

Desde o início da escolarização, Benjamin é levado a pensar na crítica aos manuais pedagógicos e no excesso de cuidados dos pedagogos e professores, sublinhando que uma parte não menos significativa de toda a formação se dá em um nível de espontaneidade e fora dos próprios âmbitos institucionais. A formação, portanto, sendo mais ampla que o ensino, está relacionada a situações da vida que ultrapassam o espaço escolar, sendo que essas situações também oferecem matériaprima para reflexões tipicamente filosóficoeducacionais.

Esse pensamento irá permanecer nos escritos posteriores de Benjamin, como no 
aforismo Canteiro de obras, escrito em 1927, que merece destaque pelo tom poético, um espaço onde, reconhecidamente, as vivências humanas constituem a formação, desde a tenra infância:

Elucubrar pedantemente sobre a fabricação de objetos - material educativo, brinquedos ou livros que fossem apropriados para crianças é tolice. Desde o Iluminismo essa é uma das mais bolorentas especulações dos pedagogos. Seu enrabichamento pela psicologia impede-os de reconhecer que a Terra está repleta dos mais incomparáveis objetos de atenção $e$ exercício infantis. $E$ dos mais apropriados. Ou seja, as crianças são inclinadas de modo especial a procurar todo e qualquer lugar de trabalho onde visivelmente transcorre a atividade sobre as coisas. Sentem-se irresistivelmente atraídas pelo resíduo que surge na construção, no trabalho de jardinagem ou doméstico, na costura ou na marcenaria. Em produtos residuais reconhecem o rosto que $\mathrm{o}$ mundo das coisas volta exatamente para elas, e para elas unicamente. Neles, elas menos imitam as obras dos adultos do que põem materiais de espécie muito diferente, através daquilo que com eles aprontam no brinquedo, em uma nova, brusca relação entre si. Com isso as crianças formam para si seu mundo de coisas, um pequeno no grande, elas mesmas. Seria preciso ter em mira as normas desse pequeno mundo de coisas, se se quer criar deliberadamente para as crianças $e$ não se prefere deixar a atividade própria, com tudo aquilo que é nela requisito $e$ instrumento, encontrar por si só o caminho que conduz a elas (BENJAMIN, 2009, p. 18-19).

Ao utilizar-se da crítica para desconstruir certas realidades da prática pedagógica, seu intuito era o de, justamente, encontrar um caminho para que a escola e a universidade pudessem exercer seus papéis de forma a promover a dignidade humana da forma mais adequada. $\mathrm{O}$ papel exercido pelos profissionais, no interior das instituições educacionais, tem uma função decisiva em toda e qualquer prática humana, e não somente nos ambientes escolares $e$ acadêmicos, mas na cultura como um todo. "Esta com certeza foi a missão de Friedrich Nietzsche entre a juventude escolar: ele lhe apontou alguma coisa sobre o amanhã, o ontem e o hoje das tarefas escolares". Quando a realidade é isolada de seu contexto espiritual, perde-se a relação com o todo, enquanto que a cultura torna-se refém do acaso (BENJAMIN, 2013, p. 54-55; cf. G.S. II, 1, p. 45).

Já no primeiro parágrafo do ensaio $A$ vida dos estudantes, Benjamin define o papel da crítica no contexto da realidade acadêmica, que é a de mostrar o papel do estudante e da universidade dentro do Estado. Contudo, "enquanto várias das condições para isso continuarem veladas, restará apenas libertar o vindouro de sua forma desfigurada, reconhecendo-o no presente. Somente para isso serve a crítica" (BENJAMIN, 2009a, p. 32; cf. G.S. II, 1, p. 75). A importância de Nietzsche nos discursos proferidos na ocasião de sua posse como presidente do Estudantado Livre de Berlim pode ser percebida tanto pelo teor de sua fala quanto por seu conteúdo, sobretudo no que se refere à vinculação do Estado com as instituições de ensino alemãs ${ }^{2}$.

\footnotetext{
${ }^{2}$ Apesar de o autor afirmar que a relação entre Benjamin e Nietzsche está mais distante do que próxima, torna-se importante mencionar a influência de Nietzs-
} 
Segundo Bolle, "valeria a pena explicitar o parentesco entre a Kulturkritik de Benjamin $e$ a de Nietzsche, que retratou a mesma instituição no início da era Guilhermina", uma vez que "boa parte das críticas de Benjamin ao sistema de ensino superior e secundário encontra-se prefigurada no texto de Nietzsche" (BOLLE, 1996, p. 12).

No que se refere às questões acerca do ensino, em Sobre o futuro de nossos estabelecimentos de ensino $(1872)^{3}$, encontram-se ideias caras ao próprio Benjamin: a defesa da autonomia acadêmica e dos estudos clássicos e a manutenção permanente da relação mais importante do meio escolar, isto é, a dinâmica entre mestre e discípulo. A proximidade com as teses do filósofo berlinense fica muito evidente ao se ler em Nietzsche a "enorme importância" à educação e ao ensino de jovens para a formação e o desenvolvimento do pensamento e da cultura. $\mathrm{E}$ em sua verve romântica nessa fase - a dos primeiros escritos - "seu ponto de partida é a tese de que cultura é uma determinação da natureza e não pode ser compreendida como estando separada dela". Como Benjamin, em seu contexto da formação do século $\mathrm{XX}$, Nietzsche também discorrerá, em sua época, sobre os efeitos danosos de uma reforma que não tinha como pauta principal a formação humana, portanto, seu resultado é

che nesse texto, uma vez que a relação do Estado com a universidade é um dos temas centrais do ensaio (MCFARLAND, 2013, p. 60-61).

3 "Com efeito, o ciclo de conferências proferido por Nietzsche em 1872 Sobre o futuro de nossas instituiçôes de formação constitui um texto clássico sobre o assunto. Texto-ponte entre a tradição da Bildung na época do Idealismo alemão e os programas de modernização do século XX - mal resolvidos, se pensamos na 'crise da formação' diagnosticada por volta de 1968, o ano 'que não acabou'" (BOLLE, 1996, p. 12). a da "condenação dos princípios, dos meios e dos efeitos criados pela modernização pedagógica operada nas escolas da época" (SOBRINHO, 2007, p. 10).

Segundo Bolle, Nietzsche - e esta crítica serve aos mesmos fins visados por Benjamin - revela a união disparatada:

Entre a Bildung e os valores burgueses de acumulação de dinheiro e de propriedade. Nietzsche critica também a tendência, reforçada por Hegel, de "subordinar todos os esforços de formação aos fins do Estado prussiano". Apenas graças a uma associação estudantil funcionando paralelamente à escola, os dois jovens, que são porta-vozes do filósofo, conseguem manter-se imunes diante da "exploração tão frequente nesses anos, pelo Estado, que tem pressa de moldar funcionários úteis e quer certificar-se de sua obediência absoluta através de exames excessivamente cansativos". Nietzsche põe aqui a nu um dos princípios da escola "moderna": estudar ao máximo, encher a cabeça até o limite, para evitar o ato de pensar (BOLLE, 1996, p. 12-13).

A escola, ao negligenciar a formação, a substitui pela erudição (BOLLE, 1996, p. 13). Sendo assim, a formação mais humanística não é fornecida pelas instituições educativas, que formam apenas para aquilo que ele chamará de "estabelecimentos para as necessidades da vida", em oposição aos "estabelecimentos para a cultura" (NIETZSCHE, 2007, p. 107), os quais não existem; portanto, assim começa o problema da educação humana, que só forma para uma profissão.

$\mathrm{Na}$ esteira de Nietzsche, não obstante em seu contexto específico, Ensino e valor, Benjamin discorrerá sobre o modo como os valores culturais são colocados nas institui- 
ções de ensino, sobretudo os valores estéti$\cos$ e éticos. Tais valores ficam visíveis em duas disciplinas ministradas na Realschule, a saber, o ensino da língua materna - o alemão - e o ensino de história, respectivamente. A questão de Benjamin, nesse caso, é a possível negligência ao ensino em detrimento da discutivel necessidade de transmissão de valores do presente, da atualidade; por isso, ele se questiona, logo no primeiro parágrafo: "Dá-se valor ao ensino (e, portanto, a escola)? Por qual objetivo se orienta tal valor?"(BENJAMIN, 2010a, p. 35; cf. G.S. II, 1, p. 35).

Ao mostrar como são estudadas as disciplinas humanísticas - Benjamin mostra a forma como Hermann e Dorothea, de Goethe, é analisada - , constata-se a deficiência do sistema de ensino alemão da época, que não priorizava a importância da arte tanto em seu estilo quanto em sua forma, resultando na negligência quanto à forma. A conclusão dessa análise é a de que os conteúdos dessas disciplinas não contextualizam a realidade, pois o ensino estava fundamentado por um modelo que não "movimentava" os conteúdos escolares com a dinâmica da vida (BENJAMIN, 2010a, p, 37-38; cf. G.S. II, 1, p. 36-37).

Não se pode esquecer de que a $R e$ alschule, na Alemanha, nesse contexto específico do século XIX e início do XX, era parte de um sistema educacional que preparava o estudante em formação para a vida prática, isto é, para uma profissão após a conclusão da escola, diferente do Gymnasium, que preparava para a universidade. Portanto, a ênfase em "movimentar" os conteúdos com a realidade, com a vida, deve-se à imediata colocação desse estudante no contexto do trabalho para exercer algum ofício ou profissão.

A crítica do filósofo ao ensino de história segue a mesma linha. Ao ressaltar apenas informações sobre "o desenvolvimento do direito, da educação, da arte, da ética e da psique moderna", esquece-se "a perspectiva sobre a nossa cultura". O valor da história cultural deve mostrar-se de maneira que o aprendizado esteja direcionado ao conhecimento, mostrando sua importância para o contexto do presente, permitindo, assim, que o estudante tenha a capacidade de exercer o espírito verdadeiramente crítico em sua atualidade histórica (BENJAMIN, 2010a, p. 3839; cf. G.S. II, 1, p. 37-38).

Mais adiante, Benjamin dedica-se à crítica ao Gymnasium alemão, lembrando a facilidade de apontar, diagnosticar e solucionar um problema na esfera educacional relativa à prática de ensino, pois, a pior das tarefas da crítica, fatalmente, é "a falta de pensamento", sobretudo "a falta de espírito", uma vez que "o único que podemos empreender com ela é o feito mesmo de mostrá-la" (BENJAMIN, 2010a, p. 39-40; cf. G.S. II, 1, p. 39-40). Ele realiza essa crítica no contexto do ensino das disciplinas de ciências humanas - sobretudo a língua materna, o alemão e a história - seguindo as reflexões realizadas sobre o Realschule. Para Benjamin, é difícil observar os objetivos concretos do ensino de disciplinas das ciências humanas para as escolas modernas, pois elas estão contaminadas por uma concepção humanista que beira o filisteísmo.

E aqui o filósofo novamente está pensando em Nietzsche, ao citar, neste ensaio, a segunda das Considerações Intempestivas (Sobre a utilidade e os inconvenientes da 
História para a vida), pois é lá que se encontra a defesa de que o estudo da História deve ser, sobretudo, útil à vida ${ }^{4}$. Partindo daí, Benjamin critica a reforma técnica que não atenta para a importância de aprender sobre a filosofia através de uma relação mais humanística, ao contrário, opta por manuais carregados de saberes e deveres prontos, sem capturar a verdade do espírito grego, por exemplo. Benjamin ressalta que só é possível encontrar "um esteticismo que não conhece a formação estética no seio de nossas aulas de leitura" (BENJAMIN, 2010a, p. 41; cf. G.S. II, 1, p. 41). No contexto da reforma realizada nos ginásios de sua época, Nietzsche também ressalta a displicência com que os jovens tratam o ensino dos clássicos ao preferirem autores modernos: "jovens ginasianos, a Vênus de Milo não tem a menor importância para vocês: e a seus mestres menos ainda - e eis aí a desgraça, eis aí o segredo do ginásio de hoje". Sua crítica, como é possível perceber, dirige-se também aos mestres que ignoram a formação clássica: "quem dentre vocês chegará a uma verdadeira percepção da gravidade sagrada da arte, se são pervertidos metodi-

\footnotetext{
4 "O valor que atribuímos à história pode ser também apenas um preconceito ocidental: não importa, contanto que progridamos e não fiquemos encerrados nesse preconceito! Contanto que aprendamos cada vez mais a estudar a história para servir à vida [...]! Na medida em que está a serviço da vida, a história está a serviço de uma força a-histórica: portanto, ela não poderia nem deveria jamais se tornar, nesta hierarquia, uma ciência pura, como as matemáticas. Quanto a saber até que ponto a vida tem necessidade dos préstimos da história, está é uma das questões e das inquietações mais graves que concernem à saúde de um indivíduo, de um povo ou de uma cultura. Pois o excesso de história abala e faz degenerar a vida, e esta degenerescência acaba igualmente por colocar em perigo a própria história (NIETZSCHE, 2011, p. 81-82).
}

camente a balbuciar indistintamente por si mesmos, quando se deveria ensiná-los a falar, a estetizar por si mesmos" (NIETZSCHE, 2007, p. 80). Essa verdadeira formação estética é defendida por Nietzsche em Sobre o futuro dos estabelecimentos de ensino, e é garantida, portanto, pela constância do estudo dos clássicos, similar ao que Benjamin defende em seus ensaios sobre o tema da reforma do espírito.

A reforma escolar, para Benjamin, é questão também para os estudantes, de modo que não pertence apenas ao âmbito pedagógico institucional ou à esfera dos professores. Em Metas e caminhos dos grupos pedagógicos estudantis nas universidades alemãs, ao referir-se às correntes pedagógicas alemãs das universidades, ele confirmará o que está sendo desenvolvido até aqui: a ideia segundo a qual os estudantes, como nova geração, estão preocupados com o futuro, e seu envolvimento com uma reforma envolve algo muito mais amplo do que pretensões partidárias ou ideológicas. Justamente em nome de uma tarefa que é crítica, o jovem abre o caminho de sua atuação social, não como movimento social, mas enquanto um modo de vida, sendo que este é o propósito mais fundamental de todos (BENJAMIN, 2010d, p. 62; cf. G.S. II, 1, p. 60-61).

Nesse ensaio, que é a reprodução da fala de Benjamin no Primeiro Congresso Pedagógico Estudantil enquanto presidente do Grupo Estudantil Livre (Freie Studentschaft) - corrente de Friburgo contra a corrente de Breslau -, constata-se a tentativa de mostrar por quais caminhos deve seguir a juventude em meio às reformas pedagógicas. Por causa disso, o filósofo mostra as insufici- 
ências da primeira corrente, indicando, diante disso, a necessidade de uma nova mentalidade estudantil. Essa mentalidade está representada pelo Tropel Livre, grupo que tenta resgatar as tradições dos estudantes e suas associações. Antes que se deter em minúcias sobre as divergências entre os grupos estudantis, o que importa é o trato de Benjamin quanto às questões de ordem filosóficoeducacional, tal como a ideia segundo a qual a atividade juvenil deve ser desenvolvida de modo a unir a dimensão individual e coletiva, já que "faltam as conexões entre a pessoa e o trabalho". Para Benjamin, o Tropel Livre é o grupo mais próximo do espírito ou da "nova concepção da vida estudantil", pois foi ele que conseguiu "situar a juventude no centro do sentimento estudantil moderno" (BENJAMIN, 2010d, p. 63; cf. G.S. II, 1, p. 61-62).

A reforma educacional deve ser feita partindo dos interesses e das necessidades dos estudantes; não deve ser algo que deve ser buscado externamente. Por isso, inserido e falando a partir de seu próprio universo estudantil, Benjamin afirma que "nossos grupos tentam promover de maneira imanente (por assim dizer) a reforma universitária de dentro para fora" (BENJAMIN, 2010d, p. 66; cf. G.S. II, 1, p. 65-66). Deste modo, não é através de uma ou outra corrente pedagógica, ou então, da ideia de algum reformista, que se encontrará a maneira verdadeira de aplicar ideias pedagógicas. Daí que, como estudante e jovem que era, o filósofo afirma: "não estamos tentando descobrir quais dos reformadores escolares de hoje temos que seguir, mas estamos tentando desenvolver as coisas a partir de nós mesmos". As questões que devem fazer parte de uma reforma educacional devem ser "perguntas desde o espírito da juventude, ou então que as desperte". Na sequência, ele afirma que para saber exatamente o que deve ser feito, torna-se importante atentar para duas coisas da esfera da práxis pedagógica: "a comunidade estudantil como tal e o modo pela qual ela desenvolve a partir de si mesma o objeto pedagógico como seu primeiro objeto, à maneira de um espelho de suas próprias necessidades e esforços" (BENJAMIN, 2010d, p. 65; cf. G.S. II, 1, p. 64).

Ainda nesse texto, Benjamin reafirma o que já está presente nos outros ensaios do período pedagógico, visto que seu interesse passa muito longe da reforma estritamente técnica, porque, para ele, ao se realizar uma reforma educacional, há, ao mesmo tempo, uma confirmação, uma espécie de "cunhagem", selando o que será o espírito da juventude. Portanto, dentro do âmbito das mudanças a serem realizadas no universo pedagógico, "nosso interesse se enquadra onde se confrontam a juventude e os valores culturais, em uma nova pedagogia filosófica" (BENJAMIN, 2010d, p. 66; cf. G.S. II, 1, p. $65)$.

Essa reforma educacional é vista como algo que ultrapassa o âmbito institucional, pois, ao partir das próprias vivências individuais até as associações e agremiações estudantis, entende-se que a busca é pela reforma das mentalidades, ao encontro da própria tomada de consciência ainda por descobrir. Diante disso, sem uma necessária percepção de que existe uma tarefa, um destino ou um caminho trilhado apenas pelo modo de vida e de pensamento próprio da juventude, a tarefa de uma reforma técnica 
seria incompleta ou infértil. É nesse sentido que Benjamin insistentemente reafirma em seus ensaios pedagógicos a necessidade de despertar para o "meio-dia da vida", ou seja, para a época da juventude.

Segundo Bolle, a crítica às instituições de ensino feita por Nietzsche, que também é a denúncia de Benjamin, impressiona pela atualidade das considerações do autor de Zaratustra. Os problemas parecem se repetir, inclusive no contexto brasileiro (mesmo que das preocupações nacionais façam parte ainda as questões de ordem estrutural: salário e plano de carreira de professores, condições físicas da escola, violência, etc.). Para Bolle, o filósofo do Zaratustra faz uma:

Crítica das instituições de formação que descuidam da atenção e disciplina para com a linguagem; que fazem de tudo para banir a filosofia; $e$ que se mantêm afastadas do contato vivo com o pensamento $e$ a aprendizagem dos artistas. Com pouquíssimas exceções, a fisionomia das nossas escolas - como aliás também das nossas cidades, esse espaço de todos - se caracteriza pela ausência de estilo, ausência de filosofia e ausência de arte (BOLLE, 1997, p. 14).

Para construir essa nova pedagogia preocupada com a formação, é necessário firmar uma comunidade de estudantes que sejam autônomos ao lidar com sua realidade. Essa questão é discutida por Nietzsche na Quinta Conferência de Sobre o futuro e levantada por Benjamin em Vida dos estudantes. Nesse ensaio, o filósofo afirma que "a submissão acrítica e inerte a esse estado é um traço essencial na vida dos estudantes" (BENJAMIN, 2009a, p. 34; cf. G.S. II, 1, p. 77), conforme mencionado anteriormente. A ideia é promover a autonomia necessária para a prática da atitude crítica em relação à sua realidade escolar e acadêmica.

A autonomia é uma rua de mão dupla, uma vez que deve ser promovida tanto pelas instituições, professores e métodos de aprendizagem, quanto deve ser de responsabilidade do jovem enquanto um aprendiz consciente que exerce uma tarefa na esfera particular das instituições, assim como na vida social e cultural.

Mas como promover a autonomia efetivamente?

\section{Formação, cultura e natureza: a unidade metafísica}

Nietzsche, na Quinta Conferência de seu ensaio Sobre o futuro, revela que os métodos de aprendizagem devem se guiar pelo propósito de suscitar no jovem o desejo de conhecer o fundamento das coisas, estimulando nele "o sentido científico" do aprendizado, ou seja, "a sede de achar e inventar" pelos próprios meios. Ao incentivá-lo desde o ginásio, essa autonomia será exercida, automaticamente, no ensino superior. Mas a primeira regra da liberdade é saber obedecer e seguir princípios, pois, fazendo isso, é possível "congratular-se com os seus pontos de vista e com os seus propósitos, para poder andar por si mesmo e sem muletas. Por isso, imediatamente, ele é convidado a produzir com originalidade, e mais cedo ainda a julgar e a criticar com precisão" (NIETZSCHE, 2007, p. 124).

A resposta sobre a questão da autonomia pode ser encontrada na ideia de unidade metafísica, ou seja, pela vinculação entre formação, cultura e natureza. Essa associação encontra-se na Vida dos estudantes, em uma clara referência às ideias de $\mathrm{Ni}$ - 
etzsche, embora esteja presente também em Reforma escolar. A juventude, nesse último ensaio, é a porta-voz do que Benjamin chamará de cultura do futuro, e é essa mentalidade que deve servir como âncora e guia, assim como uma bússola - metáfora usada pelo próprio Benjamin. A relação entre natureza e cultura não é definida, talvez porque a complementaridade de uma sobre a outra é uma ideia dada. Usando uma expressão que ressoa dos ensaios nietzschianos - e assinalada em itálico para ressaltar sua importância - o filósofo berlinense vai afirmar: o que "nós [enquanto jovem falando da juventude] queremos é o cultivo do desenvolvimento natural para diante da humanidade, isto é, para a cultura. E a expressão desta nossa vontade é: educação" (BENJAMIN, 2010b, p. 14-15; cf. G.S. II, 1, p. 13-14). Portanto, a relação mais problemática da cultura é encontrar o ponto de equilíbrio entre os dois extremos, sendo "necessário encontrar uma saída para o conflito entre o desenvolvimento natural e verdadeiro (de uma parte) e a tarefa de transformar o indivíduo natural (de outra parte), uma tarefa que nunca pode ser executada sem violência" (BENJAMIN, 2010b, p. 15; cf. G.S. II, 1, p. 14).

Nietzsche também discorre sobre as duas tendências que norteiam a reforma educacional empreendida em sua época, a saber, a extensão e a redução da cultura. Contudo, o que se busca destacar aqui, por estar mais próxima aos propósitos deste artigo, é a crítica a ambos os métodos porque, de alguma forma, estão desvinculados de uma inserção mais identitária com a natureza, uma vez que "muitos pressupostos dos nossos métodos educacionais modernos levam consigo o caráter do não-natural e que as mais graves fraquezas do nosso tempo estão justamente ligadas a estes métodos antinaturais de educação" (NIETZSCHE, 2007, p. 43).

Por isso, essa nova instituição para a cultura guiada pela natureza busca uma formação de jovens que se volte a uma verdadeira missão no interior desse lugar. Para Nietzsche, essa etapa da formação da nova juventude verdadeiramente inclinada à cultura deve ser "depurada dos traços da subjetividade e elevada acima do jogo cambiante do tempo, como puro reflexo do ser imutável das coisas". Isso tudo deve ser empreendido para "preparar o nascimento do gênio e a criação de sua obra" (NIETZSCHE, 2007, p. 117).

O gênio poderia ser pensado como o mote da educação da juventude, e em Nietzsche, isso está explícito. O que a cultura dominante promove - direcionada à formação exclusivamente profissional - é o desvio da juventude de seu destino exemplar, isto é, de uma formação que encaminhe o jovem àquilo que está endereçado, "uma certa elevação moral, o instinto do heroísmo, do sacrifício". Aqueles que se encaminham para esse destino sentem "uma necessidade autêntica de cultura, conduzida por uma educação adequada e tornada um hábito: cultura que é, antes de mais nada, como já disse, uma obediência e uma habituação à disciplina que caracteriza o gênio". Nietzsche ainda afirma que um esboço dessa instituição voltada à verdadeira cultura fora feito na época de Goethe e Schiller, interrompido e "vergonhosamente desviado e cortado de suas raízes" (NIETZSCHE, 2007, p. 117118). 
Certamente, Benjamin bebe na fonte nietzschiana ao afirmar aquilo que entende por reforma escolar guiada pela verdadeira cultura. As instituições de ensino devem, ao receber o jovem, perceber que "a escola recebe uma geração insegura em todas as questões: egoísta, possivelmente ignorante, tão natural quanto inculta (tem que ser formada efetivamente na escola)" (BENJAMIN, 2010b, p. 16; cf. G.S. II, 1, p. 15).

A ideia de reforma escolar, para Benjamin, está relacionada ao âmbito da vida, a qual - noção central nesses primeiros ensaios de sua produção intelectual - e que se refletirá na existência humana em um sentido todo especial. Neste sentido, "a reforma escolar", como o próprio título do ensaio já adianta, "é um movimento cultural". E com essa afirmação, o filósofo revela o poder do qual a escola dispõe em um âmbito mais geral. Ao mesmo tempo, e mediante uma acepção mais ampla, a escola é o lugar de transmissão de saberes específicos. Certamente todos concordam com isso, mas visto de um modo mais panorâmico e contextualizado na realidade, Benjamin afirma, destacando em itálico, que "a reforma escolar se encontra acima de qualquer tese científica específica". Ou seja, ao transcender seu significado individual, partindo para um sentido mais filosófico-pedagógico, ela "é uma ideia, um programa ético de nossa época; sem dúvida, não no sentido de que todos nós temos que defendê-lo, mas com a exigência de que todos nós tomemos o partido diante dele" (BENJAMIN, 2010b, p. 13-14; cf. G.S. II, 1, p. 13). Portanto, a escola é uma manifestação cultural que exerce um papel central na vida, em sua totalidade e unidade.
Ainda na tentativa de encontrar o verdadeiro sentido da palavra cultura, amplamente usada em seus diversos significados nas distintas áreas do conhecimento, Benjamin propõe pensá-la a partir de algumas questões que são parte da autêntica reforma escolar. Parodiando uma frase de Schiller ("O que significa e com que objetivo se estuda a história universal?"), ele se questionará sobre "o que significa e com que objetivo queremos a reforma escolar". E discorrendo a partir da definição de Pannwitzz de educação, como "a reprodução dos valores espirituais", questiona-se sobre o significado dos mesmos (BENJAMIN, 2010b, p. 14; cf. G.S. II, 1, p. 13). O filósofo utiliza também a metáfora sexual da reprodução ${ }^{5}$ para mostrar como os valores são da ordem do natural, pois se vive e se cresce ultrapassando a dimensão individual, de modo que a natureza humana age e pensa "sub specie aeternitatis", portanto, "ao educar, vivemos e atuamos sub specie aeternitatis". Contudo, essa ordem natural, como lembra Benjamin, não se origina do aspecto biológico, mas é feita com consciência, é o "espírito que está estabelecendo metas" (BENJAMIN, 2010b, p. 14; cf. G.S. II, 1, p. 13-14).

Como dito anteriormente, a educação, dessa forma, é "expressão desta nossa vontade" de cultura. A segunda questão colocada por Benjamin é justamente sobre os valores que se buscam reproduzir, ou seja, o significado da verdadeira reforma espiritual é a revisão desses mesmos valores que, ao serem reproduzidos, são automaticamente transmitidos como herança cultural aos jovens. Essa revisão pretende, consequentemente, ampliar o conhecimento e a necessi-

\footnotetext{
${ }^{5}$ Cf. WEIGEL.
} 
dade iminente de encontrar a "veracidade nos métodos educacionais" (BENJAMIN, 2010b, p. 15; cf. G.S. II, 1, p. 14). E a escola, nessa direção, será a responsável pela "cultura do futuro" - mediada pela juventude, pois é nela que se encontram "as imagens trazidas do país do futuro". Portanto, ela está entre a reforma escolar e a cultura. É nessa direção que se encaminha a pedagogia moderna: "criar espaço para a cultura que está surgindo" (BENJAMIN, 2010b, p. 16; cf. G.S. II, 1, p. 15-16).

A ideia de unidade é apresentada por Fichte em Por uma universidade orgânica $(1817)^{6}$. Esse escrito ${ }^{7}$ é de fundamental importância por ser o primeiro a tratar de questões pedagógicas, tais como a relação entre mestres e discípulos, a necessária interação da escola à universidade e outros fatores caros a Benjamin ao analisar a competência das matérias ensinadas nos espaços escolares e nas instituições de ensino superior. Para Fichte, a filosofia tem a tarefa e a capacidade de fornecer uma visão abrangente e totalizadora das matérias ensinadas, pois tem uma "visão enciclopédica de todo o saber em sua totalidade orgânica". A unidade das matérias pode e deve ser incorporada pela filosofia, pois graças a ela a determinação do que é e deve ser ciência é possível. Ela possibilita ao aluno conhecer as raízes, as fontes

\footnotetext{
${ }^{6}$ Título completo: Por uma universidade orgânica Plano dedutivo de uma instituição de ensino superior a ser edificada em Berlim, que esteja estreitamente associada a uma Academia de Ciências.

7 Segundo Bernd Witte, "na reelaboração de seus discursos" - presentes no ensaio Vida dos estudantes - Benjamin inspirou-se no "Plano dedutivo de uma instituição de ensino superior a se estabelecer em Berlim", de Fichte, e em "Sobre o futuro de nossas instituições de ensino", de Nietzsche" (WITTE, 2017, p. 28).
}

e todo o caminho percorrido em determinado conhecimento. Na mesma direção, Benjamin, quando pensava que o saber era algo que não podia simplesmente ser adquirido, desconhecendo sua base, pensava que a filosofia era a detentora da verdade e, logo, criadora de um campo de resgate dos princípios nos quais estão ancorados todos os conhecimentos válidos.

Esse resgate tem por função valorizar a procura, pelos próprios alunos, das causas dos saberes; eles mesmos devem ser capazes de refazer o caminho de como se chegou à ciência da coisa ensinada. Ou seja, ao recorrer a um ideal de cultura humanista, Fichte propõe que os professores mostrem como ocorrem os processos do conhecimento ensinado em sala de aula e não somente os resultados adquiridos ao longo da história. $\mathrm{O}$ que está por trás disso é a crítica de Fichte às universidades de sua época - século XVIII -, as quais ele acredita serem "meros institutos de recitação e repetição". A filosofia, portanto, "seria matriz organizadora da universidade", resgatando seu ideal de unidade (KRETSCHMER, 1999, p. 18).

Como afirma Kretschmer na introdução ao ensaio, ao defender a unidade do conhecimento $e$ a interação entre alunos $e$ professores, Fichte sugere uma metodologia que se inicia na escola e se estende à universidade. Essa visão orgânica pretende, por consequência, criar um elo entre a instituição de ensino e a comunidade, a nação: ao buscar, com a ajuda da filosofia, essa tarefa de promover saberes que se complementam dentro da universidade, deve se formular uma ideia geral de formação do humano (KRETSCHMER, 1999, p. 18-20). 
Certamente essa ideia ressoa como utopia, uma responsabilidade colocada nos ombros de uma instituição que lida com saberes determinados e que os transmite aos estudantes com a finalidade de formar para uma profissão, mas o que talvez seja interessante subtrair desses apontamentos esboçados a partir do ensaio de Fichte - e com os quais Benjamin concordaria, pois parece querer o mesmo - é a necessidade de se olhar para o conhecimento adquirido de modo a movimentar a vida como um todo, já que se ancora em questões que envolvem a maneira pela qual aplicamos a matéria do que é ensinado. Pois o conhecimento ajuda na prática de exercer a liberdade com fins a experimentar a vida do espírito, do espírito jovem, em última instância.

Uma forma importante de experimentar essa liberdade é praticar e cultivar o conteúdo daquilo que é ensinado, considerando a capacidade crítica do jovem. É ali, precisamente, que se encontra representada todo o aprendizado e quiçá a unidade tão almejada, expressa e manifestada em atividades culturais.

\section{A crítica como tarefa do jovem}

Benjamin reinventou a crítica como gênero ao dialogar com vários ramos do conhecimento, retomando a tradição herdada do romantismo, em cuja corrente, a crítica é entendida como crítica de arte, uma forma de continuidade da obra. Ao exigir um leitor ativo, Benjamin retoma essa concepção e pensa na crítica como uma continuidade da escrita. Por isso, recorre ao fragmento, ao aforismo e, em última instância, ao ensaio como formas inacabadas do pensamento. A crítica, um dos mais importantes conceitos do romantismo, que é retomada pelo filósofo, ganhará novo relevo em sua concepção estética e, mais tarde, em sua teoria da história.

A ideia de crítica foi retirada do Primeiro Romantismo Alemão e é explorada em sua tese de 1919, O conceito de crítica de arte no romantismo alemão. Seu expoente principal foi Friedrich Schlegel. Como afirma Seligmann-Silva (1999, p. 172-173), Benjamin tinha uma formação filosófica, mas exerceu, sobretudo, a "função" de crítico literário, como se constata em suas obras, nas afinidades eletivas de Goethe e em seu livro sobre o Trauerspiel. De fato, a crítica está presente em sua obra por influência de seu texto de juventude, justamente, a tese de doutorado. E para Seligmann, portanto, ao adentrar na ideia de crítica, é necessário entender que "Benjamin teve que 'voltar' aos primeiros românticos para estabelecer o conceito e a prática da sua crítica" (SELIGMANN-SILVA, 1999, p. 173).

Desde o início de sua produção intelectual, a crítica se apresenta como o único modo de desmascarar a realidade e se reinventar, com vistas à própria formação. E Bolle apoia esse argumento, ao afirmar que:

Benjamin não defende um ativismo de superfície, mas a busca genuína, o trabalho intelectual como risco $e$ a disponibilidade para as questões que concernem à humanidade. Cedo ele percebe a viabilidade de dois caminhos de crítica social: o "discurso", orientado em ações práticas mais ou menos imediatas; $e$ o texto do escritor, visando uma ação a longo prazo. Foi por este segundo conceito de crítica que Benjamin optou, permanecendo-lhe fiel durante a vida inteira, apesar de seu engajamento pela crítica militante. O seu texto "A Vida 
dos Estudantes", embora inicialmente concebido como um discurso, "não é apelo ou manifesto", mas a demonstração filosófica de uma crise" e, com isso, uma opção pelo ensaio de crítica da cultura. [...] Benjamin define in nuce a tarefa da crítica (e da historiografia): que tipo de conhecimento do próprio tempo a geração atual dos estudantes é capaz de elaborar? Que tipo de experiências ela é capaz de transmitir aos pósteros enquanto "tradição"? (BOLLE, 2000, p. 154).

No Prefácio da revista Angelus Novus, ensaio não publicado em vida, escrito provavelmente entre 1921 e 1922, Benjamin, em um tom que corrobora a importância do gênero, definirá a crítica como "a guardiã do limiar". E essa frase não deve ser pensada apenas como ilustrativa, pois, em seu sentido mais profundo, o limiar, noção importante em Benjamin, não é fronteira, porque essa é a representação de uma coisa única, uma linha só, que divide dois espaços; não é uma coisa que está carregada de significados próprios, que só demarca a separação entre duas instâncias, já o limiar expressa múltiplas ideias, pensamentos, vidas em si mesma. $\mathrm{O}$ limite exerce fascínio porque sugere, insinua, promete, ao contrário da fronteira que esconde, que oculta (BARRENTO, 2013, p. 120-121). E é nesse sentido que é possível pensar que o jovem poderia, como nenhuma outra figura humana, ser o guardião do limiar, uma vez que ele é uma potência consciente de seu poder.

Outra expressão da crítica em seu pensamento pode ser encontrada em Trauerspiel, em cujo livro Benjamin a pensará - e esse parece ser um traço do romantismo que ain-

8 "die Kritik der Hüter der Schwelle" (BENJAMIN, 2014, p. 242). da sobrevive em sua concepção sobre o tema - como uma alegórica, uma abertura, embora ele pense ainda sob um duplo sentido. Ou seja, a crítica:

em primeiro lugar abre a sua própria leitura, isto é, não se apresenta como uma palavra final, como um juízo fechado, mas sim como um anagrama, aberto para ser lido e completado por cada leitor (reproduzindo assim o seu próprio ato de interpretação $e$ inserindo-o em um processo de potenciação, como que abrindo o "trabalho de leitura" num movimento de desdobramento - "des-obramento" - infinito). Em segundo lugar a crítica como alegórica problematiza assim como a alegoria - a relação entre os significantes e os significados - mimetizando novamente o seu objeto, a poesia, e dando um matiz estético a si própria (SELIGMANN-SILVA, 1999, p. 214).

Ainda que se esteja pensando em seus primeiros ensaios, é importante confrontar alguns momentos de seus escritos da maturidade para perceber que não há uma quebra em sua concepção de crítica, mas uma transformação, revelando a importância de enxergar em sua obra uma unidade.

Nesse momento, Benjamin está pensando na crítica por um viés construtivo, $e$, portanto, como tarefa. Ela se transforma, em sentido mais geral, como tarefa histórica: "converter, de forma pura, o estado imanente de perfeição em estado absoluto, torná-lo soberano e visível no presente, esta é a tarefa histórica". No ensaio citado, é evidente sua concepção da história, e com essa definição se esclarece a forma de conversão de um estado específico para um mais geral, pois tal estado de perfeição absoluta "só pode ser apreendido em sua estrutura metafísica". Deste modo, "o atual significado históri- 
co dos estudantes $e$ da universidade, $[e]$ a forma de sua existência no presente, merecem portanto ser descritos apenas como símile, como reflexo de um momento mais elevado e metafísico da história" (BENJAMIN, 2009a, p. 31; cf. G.S. II, 1, p. 75).

Em Pensamento sobre o festival de Gerhardt Hauptmann, expressão crítica de uma visão de juventude que percebe que deve exercer uma tarefa no mundo, Benjamin revela a falta de ideias históricas ou do sentido da existência da humanidade que apenas se deixa levar pelo turbilhão permanente do transitório. Somente em alguns momentos dessa trajetória, desse devir, alguns indivíduos isoladamente, ou então, as pessoas em grupo, conseguiram vislumbrar esse alcance histórico como uma tarefa da humanidade, uma tarefa do futuro. Esses momentos de epifania, nos quais se podem encontrar rasgos, fissuras na realidade homogênea, Benjamin os chamará de iluminação. Essa tarefa, segundo o filósofo, é algo da ordem do incondicionado. $\mathrm{O}$ presente é uma realidade potencialmente maior do que aquilo que as pessoas entendem por sentido histórico como simples feitos e realizações. $E$ isso se torna claro pelo fato de que o filósofo está buscando um tipo de sentido histórico como "tarefa que não se pode encerrar dentro de um programa de reformas, que requer um novo movimento dos espíritos e uma maneira de ver radicalmente nova". E é à juventude que pertence o título de portadora dessa tarefa; não obstante, é necessário que a mesma desperte do sono histórico em que vive (BENJAMIN, 2010e, p. 57; cf. G.S. II, 1 , p. 57).

Deste modo, a crítica de Benjamin é uma tentativa de despertar a juventude "porque ainda não tem um programa". Essa fala é um desdobramento do drama escrito por Gerhart Hauptmann - que dá nome ao ensaio - como o modelo do verdadeiro espírito daquele que lidera as lutas históricas da humanidade. A peça intitulada Festival em rimas alemãs (Festspiel in deutschen Reimen) foi escrita em comemoração ao centenário da libertação da Alemanha contra Napoleão Bonaparte. Na segunda parte do ensaio, Benjamin afirma que a solenidade dos acontecimentos da peça não está centrada nos personagens, ou na linguagem utilizada na peça, mas são "os feitos [que] se ordenam segundo o espírito; as marionetas estão confeccionadas na mesma madeira de sua ideia; e a linguagem está cheia da procura da ideia". Portanto, através desse sentido da história, as mentalidades devem ser despertadas como tarefa histórica, o que a peça de Hauptmann ilustra perfeitamente: diante do espírito "os seres humanos são apenas marionetes (que não mostram gestos ou caracteres particulares), marionetes em poder do pensamento". Nessa peça os versos desaparecem durante a fala dos personagens para o "sentido surgir de sua linguagem" (BENJAMIN, 2010e, p. 58; cf. G.S. II, 1, p. 57-58).

Pela metáfora da festa, presente durante toda a luta travada na peça de Hauptmann, entra-se no "reino da cultura", "na festa, o dia $e$ a atividade irreflexiva alcançam a consciência do espírito". Portanto, "a festa celebra a paz como sentido oculto da luta. A paz obtida trará a cultura". As peças de Hauptmann, segundo Benjamin, mostram esse sentido de luta da juventude, que tem por tarefa a abertura ao espírito (BENJAMIN, 2010e, p. 60; cf. G.S. II, 1, p. 59). 
A ideia de uma abertura histórica pelo espírito remete novamente a Nietzsche, especificamente, na segunda das Consideraçôes intempestivas (Sobre a utilidade $e$ as desvantagens da história para a vida. Nesse ensaio, ele definirá o que são os espíritos históricos, os quais conseguem associar os conhecimentos acumulados à vida. Quando Nietzsche define os espíritos históricos, por exemplo, percebe-se a similaridade com a definição de tarefa crítica endereçada à juventude tal como apresentada por Benjamin. Pois, para ele, o que definirá o ímpeto de alguém é a medida de sua força plástica, uma capacidade para ser mediador, interlocutor entre o passado e o futuro. Para Benjamin, o jovem é o portador da capacidade de lidar com a História e com o devir. Eis a definição de Nietzsche:

Qual é a força plástica (plastische Kraft) do indivíduo, do povo ou da cultura em questão, quer dizer, esta força que permite a alguém desenvolver-se de maneira original $e$ independente, transformar e assimilar as coisas passadas ou estranhas, curar as suas feridas, reparar as suas perdas, reconstituir por si próprio as formas destruídas [...]. Quanto mais a natureza profunda de um indivíduo possua raízes vigorosas, maior será a parte do passado que ele poderá assimilar ou acolher; $e$ a natureza mais poderosa e mais formidável de um indivíduo se reconheceria naquele que tivesse abolido o limite para além do qual o sentido histórico se torna usurpador e nocivo; ele poderia atrair para si e se apropriaria de qualquer acontecimento passado, próximo ou longínquo, e, por assim dizer, transformá-lo-ia em seu próprio sangue (NIETZSCHE, 2011, p. 73-74).
Para aqueles que conseguem se desenvolver dessa forma, Nietzsche os nomeará de:

espíritos históricos (historischen
Menschen), [pois] o espetáculo do
passado os lança para o futuro, in-
flama a sua coragem de viver e de
lutar cada vez mais, ilumina neles a
esperança de que a justiça está por
vir, que a felicidade os espera do ou-
tro lado da montanha que eles pre-
tendem escalar. Estes espíritos histó-
ricos acreditam que o sentido da
existência se revela progressivamen-
te no curso de um processo (Prozes-
ses); eles só olham para trás para
compreender o presente à luz do
caminho já percorrido e para apren-
der a desejar mais ardentemente o
futuro; eles não sabem o quanto,
apesar de todos os seus conhecimen-
tos históricos, pensam e agem de
maneira a-histórica, não sabem o
quanto a sua atividade de historia-
dor é ela própria comandada pela
vida, e não pela pura busca do co-
nhecimento (NIETZSCHE, 2011 , p.
79 ).

Benjamin também deseja unir vida e conhecimento. Para isso, em Metas e caminhos, a tarefa do jovem dentro do universo escolar é bastante desafiadora: "A discussão teórica nos grupos é apenas uma parte do nosso trabalho. Com a outra parte nos encontramos na própria luta da juventude, especialmente na luta da juventude escolar". Portanto, existe uma práxis estudantil muito específica aliada à atuação mais teórica: "com sua revista Der Anfang, bem como as 'aulas de reunião', onde os alunos das escolas e os estudantes universitários conversam entre si, nos relacionamos estreitamente com a juventude escolar: sabemos que a luta de- 
les é a nossa luta" (BENJAMIN, 2010d, p. 66; cf. G.S. II, 1, p. 65).

No ensaio Experiência, analisado por Muricy, a crítica é reivindicada por Benjamin como horizonte de atuação do jovem, em combate à inércia do adulto que, "canonizando o espírito, a cultura dos adultos filisteus impede-lhe a intimidade da crítica e o torna estéril". Para Muricy, o espaço de protagonismo do jovem na sociedade está delineado nesse ensaio, pois a "crítica é a intimidade com o espírito, o compromisso de trabalhar junto". Portanto, segundo a autora, "o espaço da crítica reivindicado por Benjamin é o domínio do intelectual - aqui, da juventude produtiva - em seu compromisso com o espírito" (MURICY, 2009, p. 51).

Ao inserir a crítica no horizonte de atuação do jovem, Benjamin está fundando, reivindicando, definindo uma espécie de campo de ação dessa singularidade crescente, em formação, um campo semântico, caracterizando uma juventude filosóficopedagógica. A crítica, portanto, deve ser vista como forma de atualização do presente, de tornar a história um campo aberto de encontro entre os adultos, a história acumulada, a tradição, com o presente, dando margem a uma forma inédita de pensar a realidade; e o futuro, nessa direção, encaminha-se para um lugar novo e com perspectivas emancipadoras.

É oportuno nessa discussão sobre a potência que a educação institucionalizada detém, citar novamente o clássico ensaio de Fichte, Por uma universidade orgânica. Nele, ao dividir o que é da competência da escola $e$ da universidade, Fichte afirmará que é nessa última que deverão ser estabelecidos os critérios e as normas, em suma, o modo pelo qual se deve fazer o uso da crítica (FICHTE, 1999, p. 32). Isso é apresentado pela própria forma como o aprendizado do conhecimento acumulado é orientado, como modelo vivo, não como algo morto encontrado nos livros sem relação com a realidade dinâmica. O conhecimento é processo, o modo como se chega até eles é o tipo de aprendizado próximo da ideia de crítica defendida por Benjamin, garantidora da reflexão do jovem sobre a dinâmica do saber acumulado. O que atrai, sobretudo, na defesa de uma universidade orgânica apresentada por Fichte é sua defesa da "filosofia como matriz organizadora da universidade". Isso porque a filosofia certamente é - antes de ser uma disciplina - um modo de pensamento $e$ de ação capaz de "imprimir unidade ao todo da matéria produzida" (KRETSCHMER, 1999, p. 17-18).

Logo, uma consequência da tarefa da juventude é seu lugar absoluto no limiar entre o passado e o futuro, como porta-voz da história humana, capaz de anunciar uma nova cultura, iniciando a reforma das mentalidades como um dever iminente, exercendo esse destino através de uma postura de vida. Portanto, a juventude é uma força plástica, consciência e modo de pensamento, mas também uma idade específica da vida na qual se realiza a formação humana em seu sentido filosófico, pois representa o momento da tomada de consciência acerca da importância de sua existência histórica nas instituições de educação. 


\section{Referências}

BARRENTO, João. Limiares sobre Walter Benjamin. Florianópolis: Ed. da UFSC, 2013.

BENJAMIN, Walter. A vida dos estudantes. In: Reflexões sobre a criança, o brinquedo e a educação. Trad. Marcus Vinicius Mazzari. São Paulo: Ed. 34/Duas Cidades, 2009a, p. 31-47.

Aufsätze, Essays, Vorträge. In: Gesammelte Schriften. Band II - 1. Reihe: Suhrkamp Taschenbuch Wissenschaft, 2014.

Experiência. In: Reflexões sobre a criança, o brinquedo e a educação. Trad. Marcus Vinicius Mazzari. São Paulo: Ed. 34/Duas Cidades, 2009b, p. 21-25.

. Canteiro de obras. In: Rua de mão única. Obras escolhidas volume II. Trad. Rubens Rodrigues Torres Filho e José Carlos Martins Barbosa. São Paulo: Brasiliense, 2009, p. 18-19.

. Correspondence of Walter Benjamin: 1910-1940. SCHOLEM, G.; ADORNO, T.W. (Eds.). Trad. Manfred Jacobson e Evelyn Jacobson. Chicago/London: University of Chicago Press, 1994.

Enseñanza y valoración. In: Obras libro II. Vol.1. Trad. Jorge Navarro Pérez. Madrid: Abada Editores, 2010a, p. 35-42.

La reforma escolar, un movimiento cultural. In:.Obras libro II. Vol.1. Trad. Jorge Navarro Pérez. Madrid: Abada Editores, 2010b, p. 13-16.

Metafísica de la juventud. In: Obras libro II. Vol.1. Trad. Jorge Navarro Pérez. Madrid: Abada Editores, 2010c, p. 93-107.

. Metas y caminos de los grupos pedagógicos estudiantiles en las universidades alemanas. In: Obras libro II. Vol.1. Trad. Jorge Navarro Pérez. Madrid: Abada Editores, 2010d, p. 61-67.

O conceito de crítica de arte no romantismo Alemão. Trad. Márcios SeligmannSilva. São Paulo: Iluminuras, 2011.

. Pensamientos sobre el «Festival» de Gerhardt Hauptmann. In: Obras libro II. Vol.1. Trad. Jorge Navarro Pérez. Madrid: Abada Editores, 2010e, p. 57-61.

. Romantismo: um discurso não proferido para a juventude escolar. In: O capitalismo como religião. Trad. Nélio Schneider. São Paulo: Boitempo, 2013, p. 53-57.

BOLLE, Willi. A idéia de formação na modernidade. In: GUIRALDELLI, Paulo Jr. Infância, escola e modernidade. Curitiba: Cortez, 1997, p. 9-31. 
. Fisiognomia da metrópole moderna. São Paulo: EDUSP, 2000.

CANTINHO, Maria João. Messianismo e revolução: a história secreta. EUA: Createspace Pub, 2016.

FICHTE, Johann Gottlieb. Por uma universidade orgânica. Trad. Johannes Kretschmer. Rio de Janeiro: EdUERJ, 1999.

KRETSCHMER, Johannes. Introdução. In: FICHTE, J. G. Por uma universidade orgânica. Rio de Janeiro: EdUERJ, 1999, p. 15-21.

MURICY, Katia. Alegorias da dialética: imagem e pensamento em Walter Benjamin. Rio de Janeiro: Nau Editora, 2009.

NIETZSCHE, Friedrich. Escritos sobre História. Trad. Noéli Correia de Melo Sobrinho. Rio de Janeiro: Ed. PUC-Rio, 2005.

Sobre o futuro de nossos estabelecimentos de ensino. In: Escritos sobre educação. Trad. Noéli Correia de Melo Sobrinho. Rio de Janeiro: Ed. PUC-Rio/Ed. Loyola, 2007.

READINGS, Bill. Universidade sem Cultura? Trad. Ivo Barbieri. Rio de Janeiro: EdUERJ, 2002.

SELIGMANN-SILVA, Márcio. Ler o livro do mundo. Walter Benjamin: Romantismo e crítica literária. São Paulo: Iluminuras, 1999.

STEINER, Uwe. Crítica. In: OPITZ, Michael; WIZISLA, Erdmut (org.). Conceptos de Walter Benjamin. Trad. María Belforte e Miguel Vedda. Buenos Aires: Las Cuarenta, 2014, p. 241 304.

SOBRINHO, Noéli Correia de Melo. Apresentação. In: NIETZSCHE, Friedrich. Escritos sobre educação. Trad. Noéli Correia de Melo Sobrinho. São Paulo: Editora PUC-Rio, 2007.

Recebido em: $11 / 07 / 2020$

Aprovado em: 17/10/2020 